\title{
Fetal absent/hypoplastic nasal bone: a single center follow up study from a tertiary referral hospital in India
}

\author{
Cini Sudhakara Prasad ${ }^{1}$, Radhamony Kunjukutty ${ }^{1}$, Vivek Krishnan ${ }^{2 *}$
}

\begin{abstract}
${ }^{1}$ Department of Obstetrics and Gynecology, ${ }^{2}$ Department of Fetal Medicine and Perinatology, Amrita Centre of Excellence in Fetal Care, AMRITA Institute of Medical Sciences, Kochi, Kerala, India
\end{abstract}

Received: 31 August 2020

Accepted: 06 October 2020

\author{
*Correspondence: \\ Dr. Vivek Krishnan, \\ E-mail: drvivekkrishnan@gmail.com
}

Copyright: (c) the author(s), publisher and licensee Medip Academy. This is an open-access article distributed under the terms of the Creative Commons Attribution Non-Commercial License, which permits unrestricted non-commercial use, distribution, and reproduction in any medium, provided the original work is properly cited.

\begin{abstract}
Background: This study was undertaken to determine perinatal outcomes in fetuses with absent/hypoplastic nasal bone (AHNB) when considered as a broad entity irrespective of time at which it is identified and identify subgroups with the highest risk of abnormal outcome based on screening status and associated findings.

Methods: This was an observational study involving a total of 142 pregnant women whose fetuses were identified with AHNB by ultrasongraphy (USG) during a three year period from January 2016 to December 2018. These women were offered aneuploidy screening/non-invasive prenatal testing (NIPT) or direct invasive testing either alone or in combination. Outcome data was collected and a sub-group analysis was done by dividing them into 8 subgroups based on screening status and associated findings.

Results: Out of 12758 scans done during the study period, 142 fetuses (1.11\%) were identified with AHNB. 80 (56\%) opted the biochemical screening test, 5 (3.5\%) opted NIPT while $60(42.9 \%)$ opted for invasive testing. $21(14.8 \%)$ had an abnormal karyotype. In sub-group analysis, the best outcome was seen in group 1, where the biochemical screening was negative and no other aneuploidy markers or anomalies were seen.

Conclusions: The present study confirms the association of AHNB with chromosomal disease. However, isolated AHNB with low risk in biochemical screening is rarely associated with aneuploidy. In contrast, a significant no of fetuses yielded abnormal chromosome results when AHNB was associated with high risk in biochemical screening, additional aneuploidy markers or associated anomalies.
\end{abstract}

Keywords: Hypoplastic nasal bone, Aneuploidy, Biochemical screening-combined test, Quadruple test, Invasive testChorion villus sampling, Amniocentesis

\section{INTRODUCTION}

Trisomy 21 is one of the most common chromosomal abnormalities in new born children. It causes Down syndrome, a particular combination of phenotypic features that includes mental retardation and congenital malformations with varied manifestations. Langdon Down in 1866 identified common characteristics of patients with trisomy 21 as poor skin elasticity and flat face with a small nose. ${ }^{6}$ According to the original study by Cicero et al about $73 \%$ of fetuses with Down syndrome showed no visible nasal bone at menstrual ages (MA) 11-14 weeks. ${ }^{5}$ Other syndromes like trisomy $18(55 \%)$, trisomy $13(35 \%)$ and Turners syndrome (10\%) have also been shown to be associated with absent nasal bone at MA 11-14 weeks. ${ }^{3}$

Evaluation of nasal bone therefore plays a significant role in screening for these anomalies. In the first trimester screening for trisomy 21 based on maternal age and fetal nuchal translucency (NT), inclusion of absence of nasal bone could increase the sensitivity from $75 \%$ to $93 \%$ for a fixed false positive rate $5 \%$. $^{2}$ If maternal serum free betahuman chorionic gonadotropin $(\beta-\mathrm{HCG})$ and pregnancy associated plasma protein (PAPP-A) are combined with 
these ultrasound findings the sensitivity could increase to $97 \%$ for a false positive rate of $5 \% .^{2}$

The diagnosis of absent nasal bone is relatively easy to make. Diagnosing nasal bone hypoplasia is confusing as a number of different definitions have been used in the past. Cicero et al defined it as nasal bone length of $\leq 2.5 \mathrm{~mm} .{ }^{17}$ A more apt definition uses multiples of median (MoMs) of nasal bone (NB) length for the gestational age. Nasal bone hypoplasia is then defined either by a BPD/NB ratio of $>11$ or by NB length $<0.75,0.5,0.25 \mathrm{MoM}$ for the gestational age. ${ }^{4}$ Population based nomograms also exist. A study by Prathima et al showed that in south Indian fetuses, the mean nasal bone length increased with gestational age from $3.3 \mathrm{~mm}$ at 16 weeks to $6.65 \mathrm{~mm}$ at 26 weeks in a linear relationship with a progressive increase in the fifth percentile of fetal nasal bone length with advancing gestational age. $^{7}$

We studied fetal outcomes in 142 pregnant women with absent or hypoplastic fetal nasal bone (AHNB) during pregnancy who were offered either prenatal screening by biochemistry based methods/cell-free fetal deoxyribonucleic acid (DNA) based tests or direct chromosomal studies (by chorionic villous sampling or amniocentesis). Unlike many studies that have looked at absent nasal bone and hypoplastic nasal bone as distinct entities and several others that have looked at outcomes of fetuses with absent/hypoplastic nasal bone in the first and second trimester independently, this study looks at AHNB as a broad entity and looks at perinatal outcomes from a wider perspective.

\section{METHODS}

This observational, descriptive, analytical study was conducted at Amrita Institute of Medical Sciences, a tertiary care referral hospital at, Kochi, Kerala, India. The study was performed over a period of 3 years, from January 2016 to December 2018, and involved the departments of obstetrics and gynecology and fetal medicine. A total of 142 pregnant women whose fetuses were identified with AHNB by ultrasonography (USG) were included in the study. The ultrasound scans was performed using Voluson E10 or P8 machines from GE healthcare technologies, Milwaukee, Wisconsin (WI), United States of America (USA) with a curved linear array transducer and 2 dimensional (2D) imaging. For assessment of the fetal nasal bone, 2D images were taken in the mid sagittal section of the fetal profile with the transducer held parallel to the direction of the nose identifying the nasal bone, lips, maxilla and mandible with an angle between the insonation beam and nasal bone axis close to 45 or 135 degrees, following the method described by Sonek et al. ${ }^{3}$ This view of the nasal bone should demonstrate three distinct lines in the first trimester - the nasal tip, nasal skin and nasal bone. The nasal bone was considered ossified (present) when the third line was subjectively bigger and brighter (more echogenic) than the nasal skin line (Figure 1). In all other situations, the nasal bone was considered absent/unossified. In the second and third trimesters, nasal bone was assessed in the facial profile view (mid-sagittal view of the face). Absence of an echogenic stripe below the nasal skin line was considered to imply absent or unossified nasal bone. When an echogenic line was visible, its maximum length in the antero-posterior dimension was measured in millimeters. If the length was below the $5^{\text {th }}$ centile in the chart published by Prathima et al, the nasal bone was considered hypoplastic. ${ }^{7}$ The retro nasal triangle view proposed by Sepulveda et al was used for corroboration in both trimesters. ${ }^{8}$ Ambiguous cases were resolved using 3 dimensional (3D) imaging.

Unilateral absence of nasal bone was also noted in a few cases. This is embryologically possible because the nasal bones on either side ossify from centres independent of the contralateral bone.

The study bracketed fetuses with any of these deviations as AHNB, irrespective of the laterality.

All women thus identified were offered one of three choices: universal screening by the combined test (PAPP$A$, free $\beta-H c G$, and nuchal translucency) in the first trimester or the quadruple test (alpha-fetoprotein-AFP, estriol, $\beta-\mathrm{HcG}$ and inhibin) + genetic sonogram in the second trimester; or Chorion villus sampling (CVS) or amniocentesis; or non-invasive prenatal screening (NIPS).

In those who opted for biochemical screening, the results of the screening test and the presence of other aneuploidy markers/associated anomalies were recorded. The soft markers screened for included increased nuchal translucency, a high ductus venosus pulsatility index and tricuspid regurgitation in the first trimester; increased nuchal fold thickness, aberrant right subclavian artery (ARSA) mild ventriculomegaly, echogenic intra cardiac focus, renal pelviectasis, short long bones (humerus and femur) and echogenic bowel in the second trimester. In all second trimester risk calculations, the prior screening risk was recalculated using the genetic sonogram method described by Agathakoleus et al. ${ }^{9}$

Women whose fetuses had, in addition to the AHNB, either associated soft markers or other anomalies or returned a high risk on screening, with 1:250 and 1:100 being the cut-offs for trisomy 21 and trisomy 18 respectively, were positively counselled for the direct fetal testing by CVS or amniocentesis, depending on the gestational age. Samples were analyzed using fluorescence in situ hybridization (FISH) studies for chromosomes 13, 18, 21 and sex chromosomes and also cultured for complete karyotype. All fetuses were followed up for perinatal outcomes.

For sub-group analyses, the cases were divided into 8 subgroups, depending on the bio-chemical screening results, presence of other aneuploidy markers and associated anomalies (Table 1). 

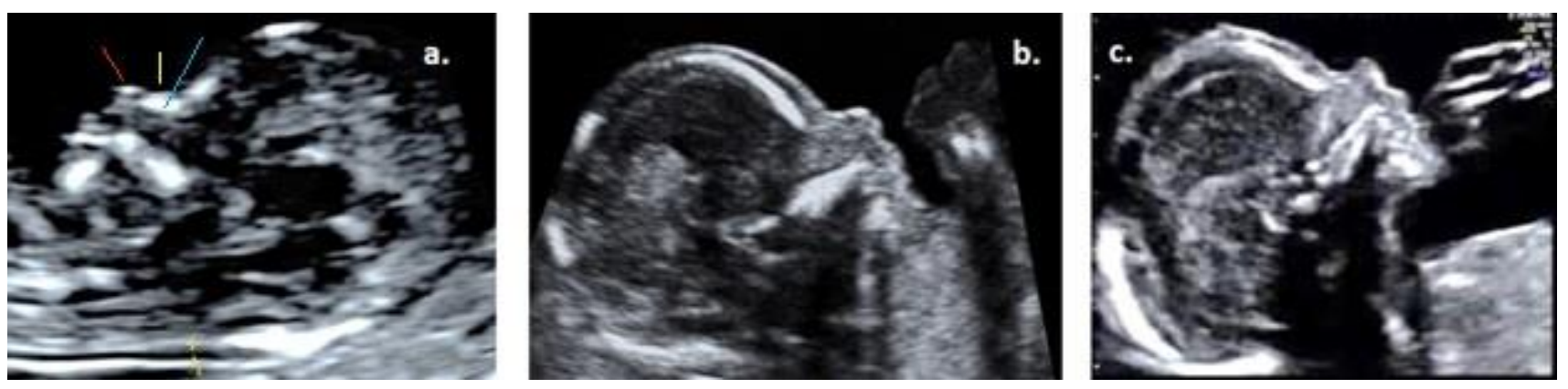

Figure 1: The three line sign (a) nasal tip (red pointer), nasal skin (yellow pointer) and nasal bone (blue pointer); (b) unossified nasal bone; and (c) hypoplastic nasal bone.

Table 1: Sub-groups based on bio-chemical screening results, presence of other aneuploidy markers and associated anomalies.

\begin{tabular}{|llll|}
\hline Group & $\begin{array}{l}\text { Biochemical } \\
\text { screening }\end{array}$ & $\begin{array}{l}\text { Additional } \\
\text { aneuploidy } \\
\text { markers }\end{array}$ & $\begin{array}{l}\text { Associated } \\
\text { anomalies }\end{array}$ \\
\hline $\mathbf{1}$ & Low risk & - & - \\
\hline $\mathbf{2}$ & Low risk & + & - \\
\hline $\mathbf{3}$ & High risk & - & - \\
\hline $\mathbf{4}$ & High risk & + & - \\
\hline $\mathbf{5}$ & High risk & + & \\
\hline $\mathbf{6}$ & Not done & + & + \\
\hline $\mathbf{7}$ & Not done & + & - \\
\hline $\mathbf{8}$ & Not done & + & + \\
\hline
\end{tabular}

Group 1 included AHNB with biochemical screening negative and no other aneuploidy markers, group 2 included AHNB with biochemical screening negative and additional aneuploidy markers, group 3 included AHNB with biochemical screening positive and no other aneuploidy markers, group 4 included AHNB with biochemical screening positive with additional aneuploidy markers, group 5 included AHNB with biochemical screening positive and additional aneuploidy markers/anomalies, group 6 included AHNB with biochemical screening not done and no other aneuploidy markers, group 7 included AHNB with biochemical screening not done and with additional aneuploidy markers, and group 8 included AHNB with biochemical screening not done, with additional aneuploidy markers/anomalies.

The study was approved by the ethical committee of the university.

\section{RESULTS}

A total of 12758 scans were done during the study period. 142 of them $(1.11 \%)$ were identified to have fetuses with AHNB. The mean age of the mothers was 28.85 years.

Of the 142 cases, $81(57 \%)$ were identified during the 1114 week scan, $56(39.4 \%)$ during the 2 nd trimester scan and five $(3.5 \%)$ during the 3 rd trimester scan. Majority of the 142 cases were referred from outside for a second opinion. In 124 cases, the nasal bone was absent while in the other 18, it was considered hypoplastic. The AHNB was bilateral in 87 cases and unilateral in 55 .

The AHNB was an isolated finding in 93 of the 142 women $(65.5 \%) .26(18.3 \%)$ fetuses had one or more additional marker, $23(16.2 \%)$ had associated anomalies like omphalocele, cystic hygroma, microretrognathia, paramedian cleft palate, double inlet right ventricle, nonimmune hydrops, atrioventricular (AV) septal defect and dysgenesis of corpus callosum. There were 3 cases of congenital heart disease and two congenital diaphragmatic hernias.

A total 80 of the 142 women (56\%) opted for a biochemical screening test following the diagnosis of AHNB. The proportion of women opting for this was expectedly higher in the sub-group of women in whom this finding was an isolated one $(66 / 80=82.5 \%) .21$ out of the 80 who underwent biochemical screening were screen positive. 8 women had undergone a screening test prior to the diagnosis of AHNB.

A total 5 patients $(3.5 \%)$ opted for NIPS, 2 of them directly and 3 following a positive screening test. 4 of the 5 were reported to be low risk. The one case that showed high risk for trisomy 21 was confirmed in due course by an amniocentesis.

A total 60 women (42.25\%) opted for invasive fetal testing (39 directly and 21 following a positive screening test) 21 of them (14.8\% of the total) had an abnormal karyotype, 20 of whom opted for termination. One trisomy 21 ended up in fetal demise. Of the abnormal karyotypes, 11 had non-disjunction trisomy 21,2 had mosaic trisomy 21,5 had trisomy 18, one had a double aneuploidy (48 XXY, +18 ), one had an unbalanced translocation, one had a derivative $\mathrm{X}$ chromosome (maternal karyotype in this case showed a balanced translocation between short arm of chromosome $\mathrm{X}$ and long arm of chromosome 4). Perinatal outcome was obtained in 138 cases. Four cases were lost to follow up. 30 women $(21.7 \%)$ opted for medical termination of pregnancy - 20 owing to an abnormal karyotype report, one whose fetus tested positive for Pelizaeus-Merzbacher disease on prenatal diagnostic 
testing in view of a previous affected child, 4 whose fetuses had other aneuploidy markers or associated anomalies but did not opt for invasive testing and 5 on personal/social grounds, none of whom opted for invasive testing.

89 of the 138 women $(64.5 \%)$ had a normal perinatal outcome. In those fetuses where AHNB was seen as an isolated anomaly $(\mathrm{N}=93), 3$ were lost to follow up. 78 $(86.7 \%)$ had a normal outcome, while 6 opted for medical termination of pregnancy (MTP) -4 of them without further testing, one because the karyotype showed trisomy 21 and another who tested positive for PelizaeusMerzbacher syndrome.

Abnormal perinatal outcomes other than aneuploidies were noted in 17 cases $(12.3 \%)$. In 5 of them, the abnormal outcomes were related to associated anomalies like congenital heart disease and diaphragmatic hernia. Other abnormal outcomes included preterm labour (5 cases; $3.6 \%$ ), fetal growth restriction (4 case; $2.9 \%$ ), low birth weight ( 2 cases; $1.4 \%$ ) and missed miscarriage (1 case, $0.7 \%)$.
There were four intra-uterine deaths. One had trisomy 21, another fetus with congenital diaphragmatic hernia (CDH) and a normal karyotye, had an unexplained intrauterine demise at 30 weeks and a fourth had severe early onset growth restriction.

For further analysis, the cases were divided into 8 subgroups based on their screening status, presence of other aneuploidy markers and associated anomalies. In the subgroup analysis, as expected, the best outcomes were seen in group 1 where the biochemical screening was negative and no additional markers or aneuploidies were noted. Leaving out the two cases that opted for MTP without further testing, 47 out of the $49(95.9 \%)$ of these fetuses had a normal outcome. 4 patients $(7.8 \%)$ opted for an invasive test directly as was suggested by the referring obstetrician. Karyotype (KT) was normal for all. Noninvasive prenatal testing (NIPT) was done for one and was negative. An abnormal outcome was noted only in two babies, both of which showed growth restriction in the second trimester. One of them ended up in an intrauterine device (IUD) at 34 weeks.

Table 2: Eight sub-groups based on biochemical screening and associated findings.

\begin{tabular}{|c|c|c|c|c|c|c|c|c|c|}
\hline Group & $\mathbf{N}$ & $\begin{array}{l}\text { KT/N } \\
\text { /abn }\end{array}$ & $\begin{array}{l}\% \\
\text { KT } \\
\text { abn }\end{array}$ & $\begin{array}{l}\text { Type of } \\
\text { aneuploidy }\end{array}$ & $\begin{array}{l}\text { NIPS } \\
/ \mathbf{N} / \\
\text { Abn }\end{array}$ & $\begin{array}{l}\text { MTP } \\
\text { aneuploidy/ } \\
\text { patient choice/ } \\
\text { others }\end{array}$ & $\begin{array}{l}\text { Normal } \\
\text { perinatal } \\
\text { outcome }\end{array}$ & $\begin{array}{l}\text { Abnormal } \\
\text { perinatal } \\
\text { outcome }\end{array}$ & $\begin{array}{l}\text { Lost to } \\
\text { follow } \\
\text { up }\end{array}$ \\
\hline 1 & 51 & $4 / 4 / 0$ & 0 & - & $1 / 1 / 0$ & $\begin{array}{l}0 / 2 / 0 \\
(3.9 \%)\end{array}$ & $\begin{array}{l}47 \\
(92.1 \%)\end{array}$ & $\begin{array}{l}2 \quad(3.9 \%) \\
\text { IUGR }-2, \text { one } \\
\text { ended up in } \\
\text { IUD }\end{array}$ & - \\
\hline 2 & 8 & $3 / 3 / 0$ & 0 & - & - & - & $\begin{array}{l}6 \\
(75 \%)\end{array}$ & $\begin{array}{l}2(25 \%) \\
\text { IUGR-1 ended } \\
\text { up in IUD } \\
\text { Preterm-1 }\end{array}$ & - \\
\hline 3 & 15 & $9 / 8 / 1$ & $\begin{array}{l}11 . \\
1\end{array}$ & Trisomy 21 & $3 / 3 / 0$ & $\begin{array}{l}1 / 2 / 0 \\
(20 \%)\end{array}$ & $\begin{array}{l}12 \\
(80 \%)\end{array}$ & nil & - \\
\hline 4 & 4 & $4 / 1 / 3$ & 75 & $\begin{array}{l}\text { Trisomy } 21 \\
\text { mosiac Trisomy } \\
21 \\
\text { Trisomy } 18\end{array}$ & - & $\begin{array}{l}3 / 0 / 0 \\
(75 \%)\end{array}$ & $\begin{array}{l}1 \\
(25 \%)\end{array}$ & nil & - \\
\hline 5 & 2 & $1 / 0 / 1$ & 50 & Trisomy 21 & - & $\begin{array}{l}1 / 0 / 0 \\
(50 \%)\end{array}$ & - & $\begin{array}{l}1(50 \%) \\
\text { MA } \\
\text { fetus with } \\
\text { trisomy } 21 \text { had } \\
\text { perimembrane } \\
\text {-ous VSD }\end{array}$ & - \\
\hline 6 & 27 & $\begin{array}{l}14 / 14 \\
/ 0\end{array}$ & 0 & $\begin{array}{l}\text { Others } \\
\text { (Pelizacus } \\
\text { Merzbacher } \\
\text { disease) }\end{array}$ & - & $\begin{array}{l}0 / 0 / 1 \\
(3.7 \%)\end{array}$ & $\begin{array}{l}18 \\
(66.7 \%)\end{array}$ & $\begin{array}{l}5(18.5 \%) \\
\text { IUGR-1 } \\
\text { Preterm- } 3 \\
\text { LBW-1 }\end{array}$ & 3 \\
\hline 7 & 14 & $9 / 5 / 4$ & $\begin{array}{l}44 . \\
4\end{array}$ & $\begin{array}{l}\text { Trisomy } 21(3) \\
\text { Mosaic Downs } \\
\text { (1) }\end{array}$ & $1 / 0 / 1$ & $\begin{array}{l}4 / 1 / 0 \\
(35.7 \%)\end{array}$ & $\begin{array}{l}5 \\
(35.7 \%)\end{array}$ & $\begin{array}{l}3(21.4 \%) \\
\text { IUGR-1 } \\
\text { LBW- } 1 \\
\text { Preterm-1 }\end{array}$ & 1 \\
\hline
\end{tabular}




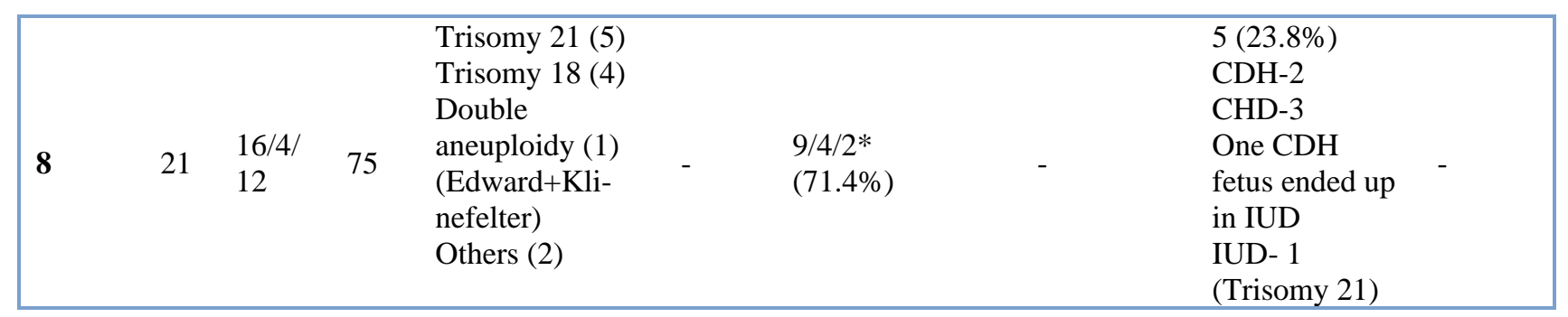

The proportion of normal babies were lower $75 \%, 25 \%$, $0 \%, 35.7 \%$ and $0 \%$ when the AHNB was seen in association with other aneuploidy markers/anomalies (groups 2, 4, 5, 7 and 8) respectively. Interestingly, group 3 , where biochemical screening showed a high risk but no other marker was noted, had more normal outcomes $(80 \%)$.

The incidence of aneuploidies was highest when the screening showed high risk and there were additional aneuploidy markers noted on scan (group 4) or in cases where a direct invasive testing was deemed the best option owing to a strong suspicion of aneuploidy on scan (group 8). $75 \%$ of fetuses in either group showed aneuploidies.

In two cases where an abnormal karyotype other than trisomy was noted, either an additional marker or a structural anomaly was seen (group 8). Another in group 6 showed Pelizaus - Merzbacher disease is the next sentence.

In groups 6-8, biochemical screening was not done either due to refusal from the patients' part, referral beyond the time limits for screening or because the ultrasound features suggested a high probability of abnormality (multiple markers, ultrasound based risk above 1 in 100, or associated anomalies).

\section{DISCUSSION}

Prenatal fetal evaluation by screening for Downs syndrome and other aneuploidies using ultrasound markers has been found effective in diagnosing chromosomal abnormalities. Assessment of the nasal bone is one of the effective secondary factors. The present cohort included 142 pregnant patients with absent/hypoplastic nasal bone.

To better define the association between absent/hypoplastic nasal bone in presence or absence of associated anomalies/aneuploidies and high and low risk in biochemical screening the cohort was divided into eight groups.

Invasive testing was done only for cases which showed high risk for aneuploidy in biochemical screening or with additional aneuploidy markers/anomalies in the ultrasound and also for referred cases from outside for amniocentesis.

Of the 142 patients 124 had absent nasal bone and 18 had hypoplastic nasal bone. Similar study Pratima et al showed 45 absent nasal bone and 40 hypoplastic out of $85 .^{1}$
Biochemical screening test was performed in 80 patients (56\%). 21 out of 80 were screen positive (high risk). All women in the high-risk group was offered invasive testing. Study done by Sonek et al based on screening patients were placed into 3 categories based on the results of the screening test, high risk, intermediate risk, and low risk. ${ }^{3}$ The high risk group was offered invasive test. In the intermediate risk group invasive testing was done on the basis of nasal bone evaluation or any other aneuploidy markers (ductus venosis Doppler or tricuspid valve).

NIPT circulating free DNA (cfDNA) was done in 5 patients, one case showed high risk for trisomy 21 which was confirmed by amniocentesis. Study done by Gil et al showed $99 \%$ detection rate of trisomy 21 with cfDNA. ${ }^{10}$

Aneuploidies were trisomy 21 (11) (57.9\%), mosaic trisomy 21 (2) $(10.5 \%)$, trisomy 18 (5) (26.3\%), which is similar to the study conducted by Cicero et al $(66.9 \%$ trisomy $21,48 \%$ trisomy (18). ${ }^{2}$ Sonek et all reported $55 \%$ trisomy $18,35 \%$ trisomy 13 and $10 \%$ Turners syndrome with absent nasal bone. ${ }^{3}$ Study done by Sonek showed hypoplastic nasal bone in $60 \%$ of trisomy 21 fetus. ${ }^{11}$ Otano et al out of 10 anueploidies, absent nasal bone was seen in 3 of the 6 trisomy 21 , one trisomy $18 .^{12}$ Odibo et al had $41 \%$ aneuploidies with AHNB and in $44 \%$ with trisomy $21 .{ }^{13}$ Bindra reported $69 \%$ of trisomy 21 with absent nasal bone. 5 had other chromosomal defects in our study. Dukhovny et al showed one other abnormal karyotype (17q 21, 31 microdeletion syndrome. ${ }^{14,15}$ Otano et al got one case of unbalanced structural rearrangement with absent nasal bone. ${ }^{12}$ Orlandi et al had one duplication of chromosome no. $5 .^{16}$

There were 5 abnormal fetal outcomes other than aneuploidies (CHD and $\mathrm{CDH}$ ) and 12 other abnormal outcomes like intrauterine growth restriction (IUGR), preterm labour, low birth weight and missed miscarriage. Dukhovny et al has 2 abnormal fetal outcome (IUGR, atypical Fryns syndrome). ${ }^{15}$

There were four intrauterine deaths $(2.8 \%)$. Orlandi et al had two intrauterine deaths among 25 absent nasal bone cases $(8 \%)$ out of the 1027 cases. $^{16}$

The cases were divided into 8 sub-groups based on the screening status. Presence of other aneuploidy markers and associated anomalies. In the study conducted by Pratima et al, there were 5 groups, group 1 showed the best results which is in concordant with Pratima et al. ${ }^{1}$ 
In group 2, when the AHNB was seen in association with other aneuploidy markers the normal fetal outcome was $75 \%$, there were no aneuploidies, Pratima et al showed $41.3 \%$ aneuploidies. ${ }^{1}$

Group 3 in which the biochemical screening was positive showed $6.7 \%$ aneuploidies as compared to $28.5 \%$ by Pratima et al. ${ }^{1}$

In group 4 where the biochemical screening was high risk and had additional aneuploidy markers had $75 \%$ aneuploidies. Pratima et al unexpectedly demonstrated normal karyotype. ${ }^{1}$

\section{CONCLUSION}

This study shows the relevance between AHNB with chromosomal abnormality. Isolated AHNB was associated with aneuploidy only in $1.07 \%$ (1/93). AHNB with high risk in biochemical screening and other aneuploidy markers or other ultrasound anomalies showed abnormal chromosomes in a significantly larger no of patients in $80 \%$ (4/5). Patients where biochemical screening was not done also with other Aneuploidy markers or anomalies yielded abnormal chromosomes in 64\% (16/25). Hence, it is recommended that this group should always be analyzed for chromosomal abnormalities.

\section{Funding: No funding sources}

Conflict of interest: None declared

Ethical approval: The study was approved by the Institutional Ethics Committee

\section{REFERENCES}

1. Dash P, Puri RD, Goyal M, Bijarnia S, Lall M, Kotecha U, et al. Absent/Hypoplastic Fetal Nasal Bone and its association with Aneuploidies. J. Fetal Med. 2015;2:75-8.

2. Cicero S, Longo D, Rembouskos G, Sacchini C, Nocolaides KH. Absent Nasal bone at 11-14 weeks of gestation and chromosomal defects. Ultrasound Obstet Gynecol. 2003;22:31-5.

3. Sonek JD, Cicero S, Neiges R, Nicolaides KH. Nasal Bone Assessment in prenatal screening for Trisomy 21. Am J Obstet Gynecol. 2006;195:1219-30.

4. Odibo AO, Sehdev HM, Stamilio DM, Cahill A, Dunn L, Macones GA. Defining nasal bone hypoplasia in second trimester Downs syndrome screening: does the use of multiples of median improve screening efficacy? Am J Obstet Gynecol. 2007;197:361.

5. Suwanrath C, Pruksanusak N, Kor-anantakul O, Suntharasaj T, Hanprasertpong T, Pranpanus S. Reliability of fetal nasal bone length measurement at 11-15 weeks of gestation. BMC Pregnancy and child birth. 2013;13:7.
6. Cicero S, Curcio P, Papageorghiou A, Sonek J, Nicolaides K. Absence of Nasal bone in fetuses with Trisomy 21 at 11-14 weeks of gestation: an observational study. Lancet. 2001;358:1665-7.

7. Bandeppa H N , Prathima R . Mid second Trimester measurement of Nasal bone length in the Indian Population. The Journal of obstetrics and Gynecology of India. 2013; 63: 256-259.

8. Sepulveda W, Wong AE, Marinez-Ten P, PerezPedregosa J. Retronasal triangle: a sonographic landmark for the screening of cleft palate in the first trimester. Ultrasound Obstet Gynecol. 2010;35:7-13.

9. Agathokleous M, Chaveeva P, Poon LC, Kosinski P, Nicolaides KH. Meta-analysis of second-trimester markers for trisomy 21. Ultrasound Obstet Gynecol. 2013;41:247-61.

10. Gil MM, Quezada MS, Revello R, Akolekar R, Nicolaides KH. Analysis of cell - free DNA in maternal blood in screening for fetal Aneuploidies: updated meta-analysis. Ultrasound Obstet Gynecol. 2015;45:249-66.

11. Cicero S, Sonek JD, McKenna DS, Croom CS, Johnson L, Nicolaides KH. Nasal bone hypoplasia in Trisomy 21 at 15-22 weeks' gestation. Ultrasound Obstet Gynecol. 2003;21:15-8.

12. Otaño L, Aiello H, Igarzábal L, Matayoshi T, Gadow EC. Association between first trimester absence of fetal nasal bone on ultrasound and Down syndrome. Prenat Diagn. 2002;22:930-2.

13. Odibo AO, Sehdev HM, Dunn L, McDonald R, Macones GA. The association between fetal nasal bone hypoplasia and Aneuploidy. Obstet Gynecol. 2004;104:1229-33.

14. Cicero S, Bindra R, Rembouskor G, Spencer K, Nicolaides KH. Integrated ultrasound and Biochemical screening for Trisomy 21 using Fetal Nuchal translucency, absent fetal nasal bone, free beta- hcg and PAPP-A at 11-14 weeks. Prenat Diagn. 2003;23:306-10.

15. Dukhovny S, Wilkins-Haug L, Shipp TD, Benson CB, Kaimal AJ, Reiss R. Absent Fetal Nasal bone. What does it mean for the Euploid Fetus? J Ultrasound Med. 2013;32:2131-4.

16. Orlandi F, Bilardo CM, Campogrande M, Krantz D, Hallahan T, Rossi C, et al. Measurement of Nasl Bone length at 11-14 weeks of pregnancy and its potential role in Downs syndrome risk assessment. Ultrasound Obstet Gynecol. 2003;22:33-9.

17. Sonek J. Nasal Bone in screening for Trisomy 21: Defining hypoplasia. Am J Obstet Gynecol. 2007;10:335-6.

Cite this article as: Prasad CS, Kunjukutty R, Krishnan V. Fetal absent/hypoplastic nasal bone: a single center follow up study from a tertiary referral hospital in India. Int J Reprod Contracept Obstet Gynecol 2020;9:4606-11. 